\title{
Mushroom Body Extrinsic Neurons in the Honeybee Brain Encode Cues and Contexts Differently
}

\author{
Syed Abid Hussaini and Randolf Menzel \\ Freie Universität Berlin, Institut für Biologie-Neurobiologie, D-14195 Berlin, Germany
}

Free-flying honeybees (Apis mellifera carnica) are known to learn the context to solve discrimination tasks. Here we apply classical conditioning of the proboscis extension response in restrained bees in combination with single-unit extracellular recordings from mushroom body (MB) extrinsic neurons elucidating the neural correlates of context-dependent olfactory discrimination. The contexts were light, colors, and temperatures, either alone or in combination. We found that bees learn context rules quickly and use them for better discrimination. They also solved a transwitching and a cue/context reversal task. Neurons extrinsic to the $\alpha$ lobe of the MB reduced the responses to the rewarded odor, whereas they increased their responses to the context. These results indicate that MB extrinsic neurons encode cues and contexts differently. Data are discussed with reference to MB function.

\section{Introduction}

An animal conditioned to respond to a cue (e.g., odor) in presence of a reinforcer such as food also learns the contexts and conditions, such as time of day, temperature, and visual stimuli. Rescorla (1972) argued that all stimuli present at the occurrence of the reinforcer are associated separately with the reinforcer, whereas Pearce (1994) favored the idea that co-occurring stimuli should be treated as unique combinations or configurations that are distinct from the elements. Elucidation of neural processing of cues and contexts may help to resolve this issue. Novel cues occur mostly in a precisely defined temporal manner along with the reward, whereas context stimuli are mostly present for longer periods of time and help to acquire and recall relevant memory. For example, in a study in humans, pairs of words were found to be best recalled under contexts similar to when learning occurred (Tulving and Thomson, 1973), and many studies with animals have documented context-specific memory formation and retrieval (Odling-Smee, 1975; Riccio et al., 1992; González et al., 2003; Matsumoto et al., 2004; Sato et al., 2006). In mammals, it has been shown that context-dependent learning depends on the hippocampus (Hirsh, 1974; Kesner et al., 1983; Phillips and LeDoux, 1992), whereas cued learning does not require the hippocampus (Hirsh, 1974; Gaskin et al., 2005), favoring the concept that cues and contexts are processed separately. It is also generally agreed that contextdependent learning is a more complex task requiring at least basic cognitive abilities (Cohen et al., 1999; Umbricht et al., 2000).

Free-flying bees differentiate between color cues, visual patterns, and directions of flights depending on where and when

Received March 9, 2012; revised Feb. 26, 2013; accepted March 8, 2013.

Author contributions: S.A.H. and R.M. designed research; S.A.H. performed research; R.M. contributed unpublished reagents/analytic tools; S.A.H. analyzed data; S.A.H. and R.M. wrote the paper.

This work was supported by German Research Foundation Grant GRK 837. We thank Dr. Ryuichi Okada for his help with training S.A.H.

Correspondence should be addressed to Randolf Menzel, Freie Universität Berlin, Institut für Biologie-Neurobiologie, Koenigin-Luise-Strasse 28/30, D-14195 Berlin, Germany. E-mail: menzel@neurobiologie.fu-berlin.de.

DOI:10.1523/JNEUROSCI.1331-12.2013

Copyright $\odot 2013$ the authors $\quad 0270-6474 / 13 / 337154-11 \$ 15.00 / 0$ these cues were learned (von Frisch, 1967; Menzel and Giurfa, 2001; Menzel, 2007). Restrained bees conditioned to an odor in the presence of another odor learn both the elements of these configural stimuli and the unique cue (Gerber and Menzel, 2000; Deisig et al., 2003). Although bees do not show conditioned responses to the visual stimuli, their responses to the olfactory stimuli are enhanced for the learned combination of olfactory cue and visual context, indicating that the visual stimuli are associatively linked to the reward facilitating memory (Gerber and Smith, 1998).

To understand the neural mechanisms underlying contextdependent learning, we looked at mushroom body (MB) extrinsic neurons and focused on those exiting the $\alpha$ lobe $(\alpha \mathrm{L})$ at the $\beta$ exit (Rybak and Menzel, 1993). MBs are high-order integration centers of the insect brain known to be involved in learning and memory formation (Heisenberg, 2003; Davis, 2011; Menzel, 2012). The $\alpha \mathrm{L}$ output neurons receive input from MB intrinsic neurons, the Kenyon cells, which in turn receive inputs from various sensory modalities, such as visual, tactile, and olfactory (Gronenberg, 1986; Rybak and Menzel, 1993).

Our aim was to unravel whether $\mathrm{MB} \beta$ neurons change their responses differently for cue and context. Behavioral experiments helped us to optimize the context-dependent learning protocol that was then combined with single-unit extracellular recordings of $\mathrm{MB}$ $\beta$ neurons.

\section{Materials and Methods}

We custom built a setup for context-dependent learning (Fig. 1) that consisted of three parts. (1) An odor delivery device (hereafter referred to as olfactometer) blew continuous stream of air over the bee's antennae and delivered odors with precise timing (Galizia et al., 1997; Komischke et al., 2002). (2) A light source with flexible light guides (KL 1500 LCD; Schott) illuminated the reflective paper placed in front of the honeybee. Two color filters (Tokyo blue \#071, transmission maximum at $460 \mathrm{~nm}$; and Medium yellow \#010, transmission at $>540 \mathrm{~nm}$; Roscoe) were used as color contexts by inserting them into the filter slide of the light source. (3) A heating/cooling device was built to deliver hot (up to $34^{\circ} \mathrm{C}$ ) or cold (up to $18^{\circ} \mathrm{C}$ ) air. 


\section{Context-dependent learning setup}

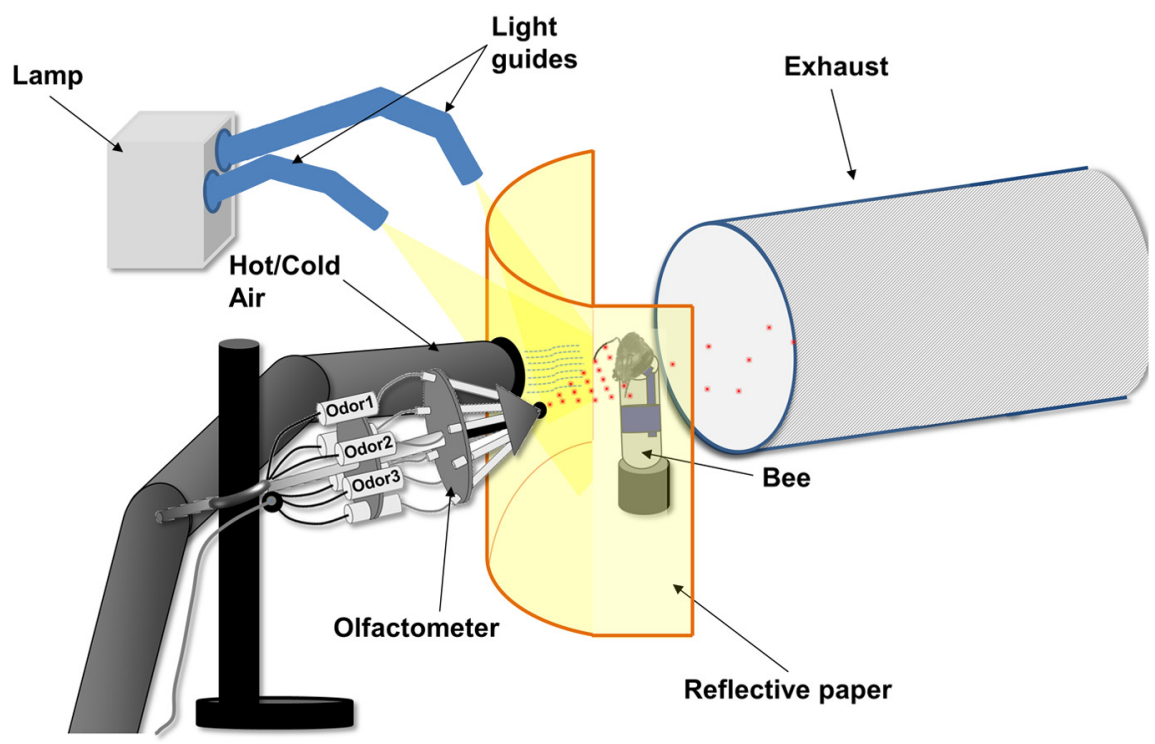

Figure 1. Context-dependent learning setup. A bee harnessed vertically in a tube was placed into a holder facing a white curved reflective paper, with two holes in it, one for the outlet of an olfactometer delivering odors to the antennae of the bee, and the other for the outlet of hot or cold air. An exhaust behind the bee continuously removed odors. The white reflective paper was illuminated with the help of two light guides that were attached to a lamp with a switchable color-filter assembly to change colors.

Foraging (female) honeybees (Apis mellifera carnica) were caught at the entrance of the hives $24 \mathrm{~h}$ before an experiment. They were fed $30 \%$ sucrose solution and kept overnight under $12 \mathrm{~h}$ light/dark cycle in a humid box at $\sim 25-27^{\circ} \mathrm{C}$. The next day they were cold anesthetized on ice and fixed inside plastic restraining tubes such that only the mandibles, proboscis, and antennae could move freely (Bitterman et al., 1983). For electrophysiological experiments, the scapes of the antennae were fixed onto the head using the low-temperature melting wax eicosane (Sigma) such that only the flagellae could move.

Bees were first tested for the proboscis extension response (PER) 10 min before the beginning of the conditioning procedure by touching the antennae with $30 \%$ sucrose solution, the unconditioned stimulus (US). Only bees that demonstrated the unconditioned response (UR) were used for the experiment ( $<5 \%$ were discarded). Three chemicals, 2-octanol, limonene, and peppermint, were used as odor stimuli [conditioned stimulus (CS)]. Light (bright and dark), color (yellow and blue), and temperature (hot and cold) were used as context stimuli. Bees were conditioned by presenting them with odors in the presence of one or a combination of two context stimuli. An experiment consisted of five conditioning trials and one or more test trials (extinction trial) at different intervals after the last trial. At the end of the experiment, bees were tested for UR, and only those that responded were used for analysis. Response to odors (PER) were entered into a Microsoft Excel spreadsheet for analysis.

Electrophysiology. Custom-made copper wire electrodes were made as described previously (Mizunami et al., 1998; Okada et al., 1999, 2007). In short, two $14 \mu \mathrm{m}$ copper wires (Electrisola) were glued together and served as differential electrodes. Additionally, two $100 \mu \mathrm{m}$ silver wires were also used. All wires were connected to the differential four-channel amplifier (A-M Systems).

A restrained bee was placed under a microscope and dissected by cutting a rectangular window into the head capsule between the two compound eyes and between ocelli and antenna exposing the brain. One silver wire was inserted into the posterior eye region of the bee, which served as the ground electrode. A second silver wire was inserted between ocelli and eyes on the back of the head and recorded the activity of the M17 muscle, which fires when the bee extends its proboscis. The differ- ential electrode was lowered into the brain at the ventral aspect of the $\mathrm{MB} \alpha \mathrm{L}$ ( $\beta$ exit) using a micromanipulator. The electrode was lowered carefully until $150 \mu \mathrm{m}$ when action potentials appeared. The position of the electrode was manipulated until the signal-to-noise ratio of the neuron was at least 2. The odors (2-octanol, limonene, and peppermint) were puffed on the bee. Only those neurons that fired in response to all three odors were taken for analysis. To keep the recording stable, silicone gel (WPI) was added to the brain.

A differential amplifier (A-M Systems) was used to amplify the signals and filter them between $10 \mathrm{~Hz}$ and $10 \mathrm{kHz}$. Spike2 signal processing software (Cambridge Electronics Design) was used to acquire the recordings to the personal computer. Spike2 was also used to control olfactometer via computer keyboard. All recordings were passed through a digital filter of Spike2 to reduce fluctuations and improve signal-to-noise quality.

The resulting units were sorted with the Spike2 template matching tool to separate different units. After spike sorting, units were proof checked by overlapping all similar spikes, and if necessary they were manually separated. All spikes, including spike timing, odor markers, and context markers, were exported to a text file for analysis. During the recording, the amplitudes of the spikes varied considerably, but the template sorting method in Spike2 software was flexible enough for us to specify separate templates for increasing set of spikes and decreasing set of spikes. This ensured that all spikes were included in the analysis.

The neurons chosen for analysis were consistent in the following ways. They were recorded from the right $\alpha \mathrm{L}$ of the MB $\beta$ exit with electrode positioned close $( \pm 50 \mu \mathrm{m})$ to the same location on the surface of the brain before lowering. Only neurons between the depths of 170 and 210 $\mu \mathrm{m}$ from the surface of the brain were sampled and used for analysis. The spikes had an initial positive potential reaching a crest followed by a negative potential reaching a trough, and the crest-to-trough times for most neurons analyzed were between 1200 and $2200 \mathrm{~Hz}$. All neurons responded to the three odors: 2-octanol, limonene, and peppermint. Based on the above criteria, neurons were pooled together for analysis.

For calculating the responses of the neurons, number of spikes before and after the onset of odor and context were quantified. The following spikes were counted to normalize the firing rate: (1) 1 s before odor onset (spontaneous spike activity); (2) $1 \mathrm{~s}$ after odor onset (odor-induced spike activity); (3) $5 \mathrm{~s}$ before the context onset (spontaneous spike activity); and (4) $5 \mathrm{~s}$ after context onset (context-induced spike activity). Odorinduced spike activity was normalized by taking the ratio between odorinduced spikes (2) and spontaneous spikes (1), and context-induced spike activity was normalized by taking the ratio between contextinduced spikes (4) and spontaneous spikes (3). Both preconditioning and postconditioning spikes were normalized. We defined spike firing rate $(\triangle \mathrm{SFR})$ as the change in firing rate from preconditioning to postconditioning toward an odor or a context divided by total firing rate:

$$
\Delta \mathrm{SFR}=\frac{\text { Post conditioning }- \text { Pre conditioning }}{\text { Post conditioning }+ \text { Pre conditioning }} .
$$

A positive $\Delta$ SFR means increased neuronal firing, a negative $\Delta$ SFR means decreased neuronal firing, and $\Delta \mathrm{SFR}=0$ means no change in neuronal firing from preconditioning phase to postconditioning phase.

Statistics. All statistics were performed on Prism and R statistical and programming software. Shapiro-Wilk normality test was used to determine normality of data. For behavioral data, $G$ test and Cochran's $Q$ test were used. For electrophysiology data, two-way repeated-measures 


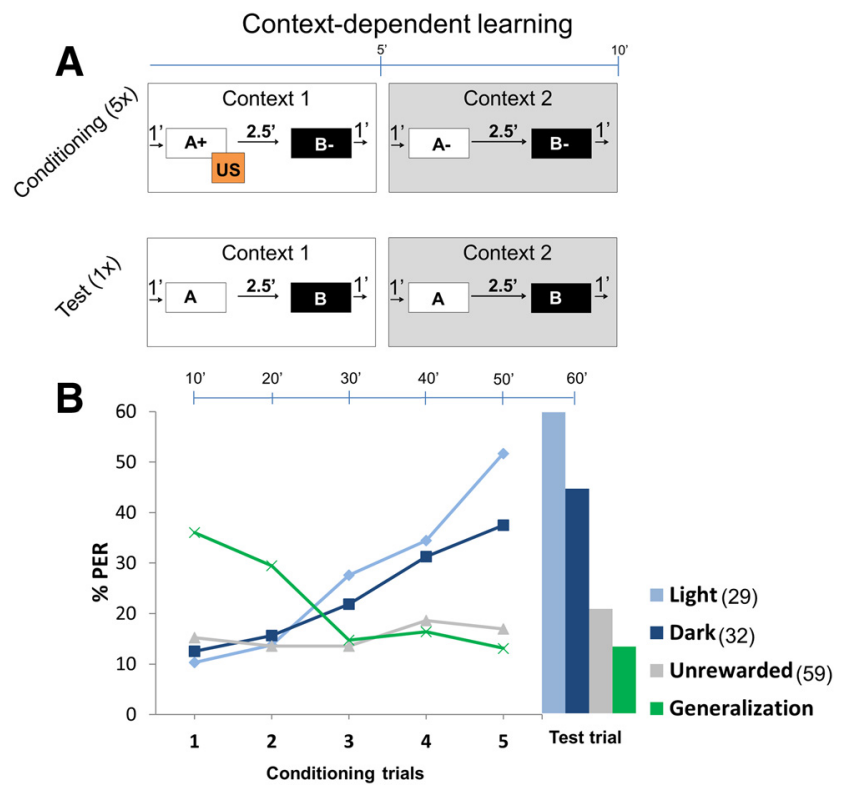

Figure 2. Context-dependent learning. $A$, Conditioning protocol. Each trial was $10 \mathrm{~min}$ long and comprised two contexts: context 1 and context 2, each for $\sim 5$ min. Light (bright light) and dark (no light) were used as context 1 and context 2 and were balanced equally. A trial started with context 1 , after 1 min odor $A$, was presented for $4 \mathrm{~s}$ followed by sucrose reward (US) for $3 \mathrm{~s}$. US overlapped with odor A for $1 \mathrm{~s}$. After $2.5 \mathrm{~min}$, odor B was presented with no US thereafter. After 1 min, context 1 was turned off and immediately context 2 was presented. After 1 min, both odors $B$ and $A$ were presented without US with an interstimulus interval of 2.5 min. Context 2 was turned off after $1 \mathrm{~min}$. This comprised one $10 \mathrm{~min}$ trial. Bees were conditioned with five such trials followed by a final test trial (or extinction trial) in which bees were presented with contexts and odors without a reward. In the control experiment, contexts and odors were presented in the same sequence as above but without any reward. $\boldsymbol{B}$, Plot shows percentage of bees showing PER across trials. Top scale bar shows time elapsed after each trial. Light blue (light context) and dark blue (dark context) curves indicate percentage of bees extending their proboscis only toward the rewarded odor in context 1 but not context 2 (see Table 1). With increasing trials, bees showed better learning toward light context than dark context (not significant). Green curve shows percentage PER toward rewarded odor in both contexts (generalization). Generalization is high in the beginning but reduces with trials as bees show better context learning. Gray curve (unrewarded control experiment) shows pooled responses for all odors in both contexts, which was always $<20 \%$. Context learning toward light and dark contexts was significantly higher compared with other groups ( $G$ test: light, $G=12.62, p<$ 0.01 ; dark, $G=5.43, p<0.05)$. Numbers in legend indicate $n$.

ANOVA with Tukey's posttest, one sample $t$ test, and Pearson's product moment correlation coefficients were used. Plots were made using Microsoft Excel spreadsheet.

\section{Results}

\section{Bees show context-dependent learning}

To address the question whether bees learn the contexts in our test conditions, we presented the bees with two contexts and two odors. In context 1 , only odor A was rewarded and odor B not rewarded, and in context 2, neither odors A and B were rewarded. The two contexts were bright (white light) and dark (no light). Note that, in the dark context, a red light was used (wavelength, $630 \mathrm{~nm}$ ) that was beyond the visible spectrum of bees' vision. The rewarded odors are indicated by the + symbol and unrewarded odors by the - symbol. Each conditioning trial lasted for $10 \mathrm{~min}$ (Fig. 2A). A trial started with an onset of first context (context 1) followed by the first odor $(\mathrm{A}+) 1$ min later, which was puffed onto the bee's antennae for $4 \mathrm{~s}$ with an overlap of $1 \mathrm{~s}$ with $3 \mathrm{~s}$ sucrose reward (US). After $2.5 \mathrm{~min}$, a second odor (B-) was puffed onto the antennae but without the US. Immediately after the offset of context 1, a second context (context 2) was turned
Table 1. Context-dependent learning: types of PERs of an individual bee during context-dependent learning at the end of each trial that consists of two odors in context 1 and two odors in context 2

\begin{tabular}{lll}
\hline & Context 1: $A+B-$ & Context 2: $A-B-$ \\
\hline Context learning & A1 B0 & A0B0 \\
Generalization & A1 B0 & A1B0 \\
& A1 B1 & A1B1 \\
No learning & A0 B0 & A0B 0
\end{tabular}

$A+$ means that odor $A$ was rewarded, and $B-$ means that odor $B$ was not rewarded. $A 1$ means response toward $\operatorname{odor} A$, and $B 0$ means no response toward odor $B$. The expected response toward $A+B-$ in context 1 was $A 1 B 0$ and toward $A-B-$ in context 2 was $A 0 B$. Bees that showed these responses were known to have learned the contexts correctly. Bees that showed same response ( $\mathrm{A} 1 \mathrm{~B} 0$ or $\mathrm{A} 1 \mathrm{~B} 1$ ) in both contexts were known to generalize. Bees that did not learn the context showed no response ( $\mathrm{AO} \mathrm{BO})$.

on. After 1 min, odor A - was puffed without any reward, and 2.5 min later, odor B- was also puffed without any reinforcing reward. The trial ended with the offset of context 2. Each trial consisted of two 5 min contexts. After 5 such conditioning trials, a sixth trial, the test or extinction trial, was presented to the bees without any US. The sequence of contexts, odors, and rewards were changed in every experiment. In the control experiment, bees were subjected to the same sequence of odors and contexts but without any sucrose reward.

When bees learned an odor, they responded to the odor puff by extending their proboscises in anticipation of sugar reward. We used "1" or " 0 " to indicate a response or a no response of the bees toward an odor. For example, A1 B0 means that bees responded (extended their proboscises) to odor A and did not respond (did not extend their proboscises) to odor $\mathrm{B}$. The expected response toward odors $\mathrm{A}+\mathrm{B}-$ in context 1 was $\mathrm{A} 1 \mathrm{~B} 0$ and toward odors $\mathrm{A}-\mathrm{B}-$ in context 2 was A0 B0 (Table 1). To test how many bees correctly learned the rewarded context and not the unrewarded context, we calculated the percentage of bees showing $\mathrm{A} 1 \mathrm{~B} 0$ in context 1 and $\mathrm{A} 0 \mathrm{~B} 0$ in context 2 . Initially, bees generalized toward the rewarded odor A (Fig. 2B, green curve) but quickly learned the context rule and showed higher response toward odor A only in context 1 . By the end of the final test trial, bees learned both light and dark contexts (Fig. 2B, light and dark blue, respectively), successfully showing significantly higher responses ( $G$ test: light, $G=12.62, p<0.01$; dark, $G=5.43$, $p<$ $0.05)$ compared with the control group (gray). Although the bees showed better context discrimination with light context (58\%) compared with dark context (44\%), this was not significant. Response toward unrewarded odor B was always $<20 \%$ (data not shown). Also, control bees that were placed in both contexts and puffed with same sequence of odors but without rewards showed $<20 \%$ response (gray curve).

\section{Bees learn an odor reversal rule during context-dependent learning}

Next we tested whether bees could reverse a previously acquired learning rule, a more complex form of learning, in which they had to reverse their responses toward the rewarded odors depending on the context. For example, in context 1, odor A was rewarded and odor $\mathrm{B}$ was not rewarded $(\mathrm{A}+\mathrm{B}-)$, whereas in context 2 , odor $\mathrm{A}$ was not rewarded and odor $\mathrm{B}$ was rewarded $(\mathrm{A}-\mathrm{B}+)$. Bees that learned this reversal rule extended their proboscises toward odor A in context 1 and toward odor B in context 2 . In other words, the expected response was $\mathrm{A} 1 \mathrm{~B} 0$ for context 1 and A0 B1 for context 2. To test reversal learning in bees toward context 1 versus context 2 , we used four context groups: for group 1 (color), blue versus yellow; for group 2 (low temperature range), $26^{\circ} \mathrm{C}$ versus $32^{\circ} \mathrm{C}$; for group 3 (high temperature range), 


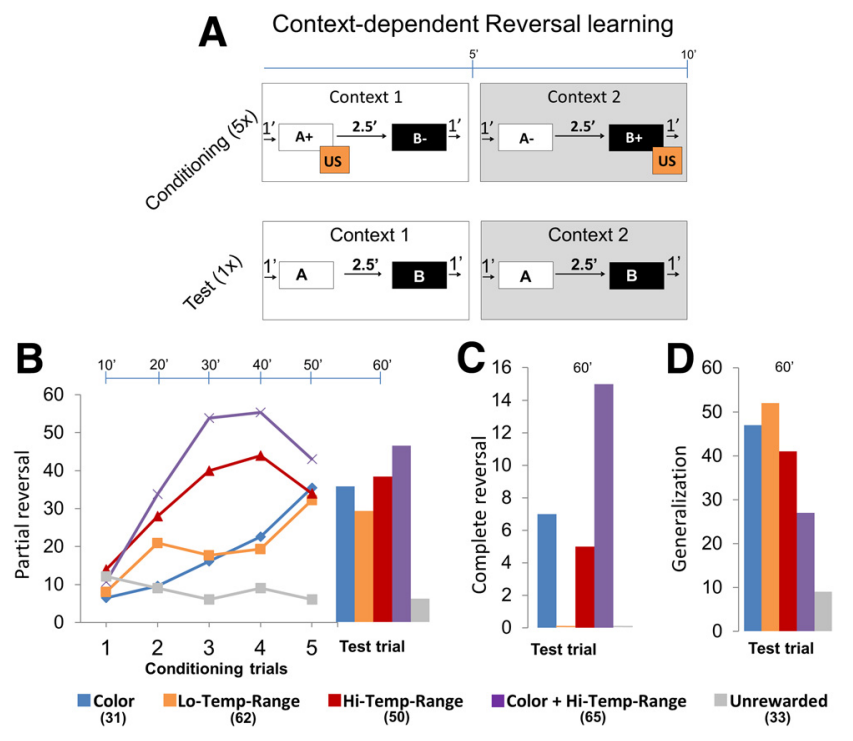

Figure 3. Context-dependent reversal learning. $A$, Conditioning protocol. Each trial was 10 min long and comprised two contexts: context 1 and context 2 , each for $\sim 5$ min. Bees were randomly assigned to four groups: (1) group 1: colors (blue vs yellow); (2) group 2: low temperature range $\left(26^{\circ} \mathrm{Cvs} 32^{\circ} \mathrm{C}\right)$; (3) group 3: high temperature range $\left(19^{\circ} \mathrm{C}\right.$ vs $\left.32^{\circ} \mathrm{C}\right)$; or (4) group 4: colors + high temperature range (yellow $+32^{\circ} \mathrm{C}$ v blue $+19^{\circ} \mathrm{C}$ ) were used as context 1 and context 2 and were balanced equally. A trial started with context 1 for $1 \mathrm{~min}$ and then odor $A$ was presented for $4 \mathrm{~s}$ followed by sucrose reward (US) for 3 s overlapping for $1 \mathrm{~s}$ with A. After $2.5 \mathrm{~min}$, odor B was presented but without any US. After 1 min, context 1 was turned off and immediately context 2 was presented. After $1 \mathrm{~min}$, odor B was presented and paired with US. After 2.5 min, odor A was presented but without any US. Context 2 was turned off after $1 \mathrm{~min}$. This comprised one trial. Bees were conditioned with five such trials followed by one test trial. In the unrewarded control experiment, the contexts and odors were presented in the same sequence but without a reward. $\boldsymbol{B}$, Plot shows percentage bees showing partial reversal in a particular trial, for example, if a bee showed PER toward odor $A$ in context 1 and no PER toward odor $A$ in context 2 , whereas if a bee showed no PER to odor $B$ in either context, it is said to have learned the context rule albeit only partially (Table 2). Most of the bees showed significant partial reversal toward the rewarded context compared with the unrewarded context. Bees that were subjected to combination of two contexts color + high temperature range showed the highest partial reversal. C, Complete reversal was one in which bees showed PER toward only rewarded odors in each context. Bees subjected to combined context color + high temperature range showed the most number of complete reversals. $\boldsymbol{D}$, Bees that showed same response to odors in each context were said to generalize. Bees from context color + high temperature range showed the least generalization. $G$ test: group $1, G=$ $9.19, p<0.01$; group $2, G=7.99, p<0.01$; group $3, G=12.40, p<0.01$; group $4, G=$ $18.99, p<0.01$. Numbers in legend indicate $n$.

$19^{\circ} \mathrm{C}$ versus $32^{\circ} \mathrm{C}$; and group 4 (color + high temperature range), yellow $+32^{\circ} \mathrm{C}$ versus blue $+19^{\circ} \mathrm{C}$. The bees were randomly allocated to one of the four groups. Each group was conditioned to two odors in the presence of two contexts using the differential conditioning paradigm.

One conditioning trial lasted $\sim 10 \mathrm{~min}$ with $5 \mathrm{~min}$ for each context (Fig. 3A). The experiment started with the onset of the first context (context 1): after $1 \mathrm{~min}$, the first odor $(\mathrm{A}+$ ) was puffed on to the antennae for $4 \mathrm{~s}$ with an overlap of $1 \mathrm{~s}$ with $3 \mathrm{~s}$ sucrose reward (US). After $2.5 \mathrm{~min}$, a second odor (B-) was puffed on to the antennae without reward. After $1 \mathrm{~min}$, context 1 was turned off and immediately the second context (context 2) was turned on. After $1 \mathrm{~min}$, odor B+ was puffed on to the antennae followed by the US, and after $2.5 \mathrm{~min}$, odor A - was puffed on to the antennae without US. The conditioning trial ended with the offset of context 2. Therefore, each conditioning trial consisted of two contexts with four odor presentations in which two different odors were rewarded in two different contexts. After five conditioning trials, a final test trial was presented without any
Table 2. Reversal learning: types of PERs of an individual bee during reversal learning at the end of each trial that consists of two odors in context 1 and two odors in context 2

\begin{tabular}{lll}
\hline & Context 1: $A+B-$ & Context 2: $A-B+$ \\
\hline Complete reversal & A1 B0 & A0 B1 \\
Partial reversal & A1 B0 & A0 B0 \\
& A1 B0 & A1 B1 \\
& A1 B1 & A0 B0 \\
Generalization & A1 B0 & A1 B0 \\
No learning & A1 B1 & A1 B1 \\
\hline
\end{tabular}

$A+$ means that $A$ odor was rewarded, and $B-$ means that $B$ odor was not rewarded. $A 1$ means response toward odor $A$, and $B 0$ means no response toward odor $B$. The expected response after context learning (Fig. $3 A$ ) toward $A+$ $B$ - was $A 1 B 0$ in context 1 and toward $A-B+$ was $A 0 B 1$ in context 2 . This is complete reversal. Apart from this, bees also showed partial reversal with correct responses only in one of two contexts. Bees also showed generalization with same responses in both contexts ( $\mathrm{A} 1 \mathrm{~B} 0$ or $\mathrm{A} 1 \mathrm{~B} 1$ ). Finally, bees that did not learn either context showed no response $(\mathrm{AO} B \mathrm{~B})$.

reward (extinction trial). Each of the four groups had a control in which odors and contexts were presented in the exact same sequence but without any reward. In all experiments, the orders of context and odor presentations were changed.

The purpose of this experiment was to determine whether contexts provide suitable information for the bees to be able to tell apart whether an odor is rewarded or not. The criteria were based on the successful prediction of bees to foresee an oncoming reward based on context alone. If bees were successful in predicting that a particular odor precedes a reward in one context while not in other context, then we called it a partial reversal. If bees could correctly predict oncoming rewards for both odors in both contexts, then we called it a complete reversal. If they showed the exact same response in both contexts, then we called it generalization.

Based on the PER displayed by each bee at the end of each trial, responses were grouped (Table 2) as complete reversal, partial reversal, generalization, and no learning. For complete reversal, bees learned to reverse their responses based on the context. They showed response $\mathrm{A} 1 \mathrm{~B} 0$ toward $\mathrm{A}+\mathrm{B}-$ odors in context 1 and response $\mathrm{A} 0 \mathrm{~B} 1$ toward $\mathrm{A}-\mathrm{B}+$ odors in context 2. For partial reversal, bees showed reversal only partially as they responded toward rewarded odors or did not respond toward unrewarded odors only in one of the two contexts. It was clear from their responses that they recognized the odors as differently rewarded CSs in the two different contexts, for example, A1 B0 toward A+ $\mathrm{B}$ - in context 1 and $\mathrm{A} 0 \mathrm{~B} 0$ toward $\mathrm{A}-\mathrm{B}+$ in context 2 (for other possible responses, see Table 1 ). When bees generalized, they extended their proboscises toward the same odors or all odors in both the contexts. Here the bees never learned that two contexts were different, for example, A1 B1 toward A $+\mathrm{B}-$ in context 1 and $\mathrm{A} 1 \mathrm{~B} 1$ toward $\mathrm{A}-\mathrm{B}+$ in context 2 . Bees that did not learn at all showed A0 B0 response in both contexts. Finally, control bees that were tested with only odors (no reward throughout the training) also showed A0 B0 response.

Among the four groups [blue vs yellow (group 1), $26^{\circ} \mathrm{C}$ vs $32^{\circ} \mathrm{C}$ (group 2 ), $19^{\circ} \mathrm{C}$ vs $32^{\circ} \mathrm{C}$ (group 3 ), and yellow $+32^{\circ} \mathrm{C}$ vs blue $+19^{\circ} \mathrm{C}$ (group 4 )], group 1 bees responded gradually during the conditioning, and at the end of conditioning, 35\% of the bees showed partial reversal (Fig. $3 B$ ) and 7\% showed complete reversal (Fig. 3C). The yellow color served as a more salient context than the blue color. Generalization was 47\%. Group 2 bees showed the lowest response of all groups at the final test trial. After six trials of $26^{\circ} \mathrm{C}$ and six trials of $32^{\circ} \mathrm{C}, 30 \%$ of bees showed partial reversal and none of the bees showed complete reversal. Also $\sim 52 \%$ of the bees showed generalization (Fig. 3D). In group 3 , the response toward the rewarded context increased gradually 
to $45 \%$ until the fourth trial and dropped to $35 \%$. Response was stronger during the $32^{\circ} \mathrm{C}$ context compared with $19^{\circ} \mathrm{C}$ context. After conditioning, nearly $39 \%$ of the bees showed partial reversal and $5 \%$ of the bees showed complete reversal. Generalization was $41 \%$. Group 4 bees showed the highest response. During the conditioning trials, nearly $55 \%$ of the bees showed partial reversal in the third trial but dropped to $42 \%$ at the fifth trial. Like in the group 3 bees, responses were stronger toward $32^{\circ} \mathrm{C}$ context compared with $19^{\circ} \mathrm{C}$ context. After conditioning the responses increased slightly to $47 \%$. Also, $\sim 15 \%$ of the bees showed complete reversal. Generalization was $36 \%$. Each of the above groups had controls that were presented with contexts and puffed with odors but without any reward. None of the groups showed complete reversal, and partial reversal was below $10 \%$. Partial and complete reversals in all groups 1-4 were significantly higher than their respective unrewarded groups ( $G$ test: group 1, $G=$ 9.19, $p<0.01$; group $2, G=7.99, p<$ 0.01 ; group $3, G=12.40, p<0.01$; group $4, G=18.99, p<0.01)$. In summary, we found that, among the four groups of contexts, the group 4 context, yellow $+32^{\circ} \mathrm{C}$ versus blue $+19^{\circ} \mathrm{C}$, provided the best conditions for reversal learning, with $>60 \%$ of bees showing complete or par-

tial reversals. Performance of bees in group 1 context (blue vs yellow) and group 3 context $\left(32^{\circ} \mathrm{C}\right.$ vs $\left.19^{\circ} \mathrm{C}\right)$ was similar, with $\sim 40 \%$ of bees showing complete or partial reversals. Performance in group 2 context $\left(26^{\circ} \mathrm{C}\right.$ vs $\left.32^{\circ} \mathrm{C}\right)$ was the lowest, with $<30 \%$ reversals of any kind. Based on these results, we chose group 4 context to be the best for studying neuronal properties during reversal learning.

\section{Neuronal activity of MB $\boldsymbol{\beta}$ neurons during learning}

We studied neurons of the MBs at the $\beta$ exit (MB $\beta$ ) of the $\alpha \mathrm{L}$ to search for neural correlates of cue and context learning because these neurons are known to respond to multiple sensory modalities and change their properties during associative learning (Mauelshagen, 1993; Okada et al., 2007; Strube-Bloss et al., 2011). We first looked at general properties of $\alpha \mathrm{L}$ extrinsic neurons, such as their firing rate (spikes per seconds), during spontaneous activity and in response to contexts and odors. In general, the firing rate of these neurons increased with the onset of contexts and odors (Figure $4 A, B$ ), but firing rates changed depending on conditioning protocols, which is discussed in the next section. The firing rate changed dramatically with the temperature context (Fig. $4 C, D$ ). During the $32^{\circ} \mathrm{C}$ context, the firing rate increased, and during $19^{\circ} \mathrm{C}$ context, firing rate decreased. The firing rate at $32^{\circ} \mathrm{C}$ was more than 10 -fold compared with that at $19^{\circ} \mathrm{C}$. Figure $4 D$ shows the firing rate of a representative $\mathrm{MB}$ extrinsic neuron during $19^{\circ} \mathrm{C}$ and $32^{\circ} \mathrm{C}$ contexts. At $19^{\circ} \mathrm{C}$, the firing rate was $<10 \mathrm{~Hz}$, but when temperature was increased, the firing rate increased to $\sim 70 \mathrm{~Hz}$ in 2 min and at 4 min the firing rate reached a saturation $(\sim 80 \mathrm{~Hz})$. When the temperature was decreased, the firing rate decreased to $<25 \mathrm{~Hz}$ in $2 \mathrm{~min}$ and saturated after $4 \mathrm{~min}$. Apart from the $\Delta \mathrm{SFR}$, the spike amplitude also increased during $32^{\circ} \mathrm{C}$ context and decreased or sometimes even disappeared during $19^{\circ} \mathrm{C}$ context (data not shown).

To compare neuronal properties before and after conditioning, we used a three-phase experimental design; (1) preconditioning phase: bees were puffed with three odors $\mathrm{A}, \mathrm{B}$, and C, in pseudorandom order two times each; (2) conditioning phase: bees were puffed with two odors A and B but only one odor was rewarded, and this was repeated five times; and (3) postconditioning phase: bees were puffed with odors A, B, and C in the same order as in the preconditioned phase. In context-dependent learning experiments, these three phases were repeated once in each context. We looked at the spontaneous neuronal activity (activity before the onset of odors or contexts) in all the experiments and calculated the interval between two spiking events [interspike interval (ISI)] during the preconditioning and post conditioning phases. We found that the ISI decreased from 27.8 $\mathrm{ms}$ in the preconditioning phase to $13.2 \mathrm{~ms}$ in the $120 \mathrm{~min}$ postconditioning phase (Fig. 4E); in other words, the spontaneous activity of the neurons nearly doubled during the course of conditioning (two-way repeated-measures ANOVA: 15 and $60 \mathrm{~min}$, $p<0.05 ; 120$ min, $p<0.01$; overall effect, $\left.F_{(3,220)}=5.44\right)$. Additionally, neuronal firing became more uniform at 15,60 , and 120 min after conditioning compared with preconditioning as indicated by a drop in SE.

\section{Olfactory differential learning: neuronal activity is reduced toward rewarded odors}

Next we looked at the responses of MB $\beta$ neurons toward the rewarded odor cues by applying a differential odor conditioning protocol (Fig. 5A) in which only one of two odors was rewarded. 


\section{Neuronal firing during Olfactory learning}

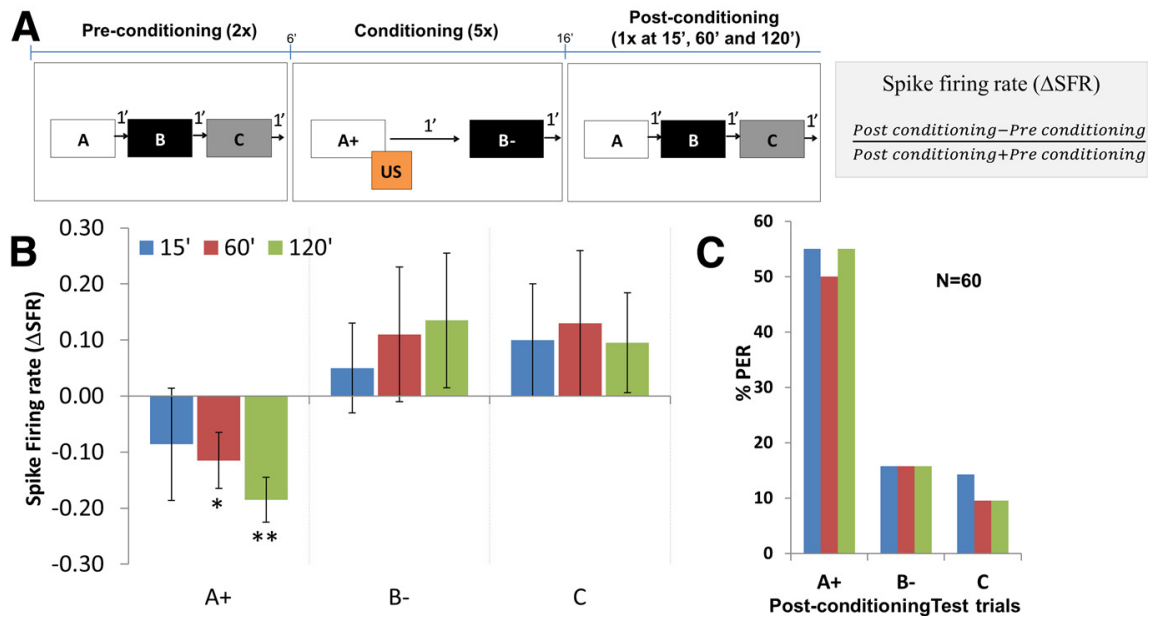

Figure 5. A, Olfactory learning protocol. Preconditioning phase: bees were presented twice with odors $A, B$, and C. Conditioning phase: odor $A$ was presented together with a sugar reward (US), whereas odor $B$ was no reward comprising one conditioning trial. Bees were subjected to five such trials. Postconditioning phase: similar stimulus conditions as in the preconditioning phase but without any reward (extinction trials). The extinction trials were presented 15,60, and 120 min after the last conditioning trial. The change in neuronal response was measured by calculating the $\triangle$ SFR (see equation) and is expressed as change in firing rate from preconditioning phase to postconditioning phase divided by total firing rate. $B$, Change in neuronal response calculated as $\triangle$ SFR toward the rewarded odor $A$ was reduced at 60 and 120 min after differential conditioning (two-way repeated-measures ANOVA: $60 \mathrm{~min}, p<0.05 ; 120 \mathrm{~min}, p<0.01 ;$ overall effect, $\left.F_{(2,177)}=335.4\right)$. Firing rate toward odors $B$ and $($ was slightly increased, but this effect was not significant. Plots show average $\triangle S F R$ for each group, and error bars represent SEM. C, Plot showing percentage PER toward rewarded odor $A+$, unrewarded odor $B-$, and neutral odor $C$. Cochran's $Q$ test: 15 min, $Q=46.08, \mathrm{df}=2, p<0.01$; $60 \mathrm{~min}, Q=41.33$, df $=2, p<0.01 ; 120 \mathrm{~min}, Q=48.67, \mathrm{df}=2, p<0.01)$.

Again, there were three phases: (1) preconditioning phase: bees received three puffs with three odors $(\mathrm{A}, \mathrm{B}$, and $\mathrm{C})$ in random sequence at $1 \mathrm{~min}$ intervals; this was repeated twice and bees were left undisturbed for $5 \mathrm{~min}$. (2) conditioning phase: bees were puffed with one odor $(\mathrm{A}+)$ followed by sugar reward (US), and after $1 \mathrm{~min}$, a second odor $(\mathrm{B}-)$ was puffed without a reward; this was repeated five times; (3) postconditioning (or extinction) phase: bees were puffed with three odors (A, B, and C, the same odors as in first phase) at 15, 60, and 120 min after the last conditioning trial. The sequence of odor presentation was the same as in the preconditioning phase. The PERs were recorded for all the three phases. The change in neuronal responses toward the odors during the postconditioning phase were compared with that of the preconditioning phase. This was done by calculating the $\Delta$ SFR across the two phases and was defined as change in firing rate from preconditioning phase to postconditioning phase divided by total firing rate.

The change in neuronal response $(\Delta \mathrm{SFR})$ toward the rewarded odor $(\mathrm{A}+)$ gradually became negative with conditioning trials and became significantly negative at the 60 and $120 \mathrm{~min}$ postconditioning trials compared with the unrewarded odor $\mathrm{B}-$ and the neutral odor $\mathrm{C}$ (Fig. 5B; two-way repeated-measures ANOVA: $60 \mathrm{~min}, p<0.05 ; 120 \mathrm{~min}, p<0.01$; overall effect, $\left.F_{(2,177)}=335.4\right)$. In addition, the change in neuronal response was significantly negative at 60 and 120 min compared with the hypothetical $\triangle$ SFR of 0 , i.e., no change in neuronal response (one-sample $t$ test: $60 \mathrm{~min}, p<0.05, t=2.72, \mathrm{df}=59 ; 120 \mathrm{~min}$, $p<0.01, t=3.45, \mathrm{df}=59$ ). With respect to behavior, $\sim 55 \%$ of the bees showed PER toward the rewarded odor $(\mathrm{A}+)$ compared with PER toward unrewarded and neutral odors (Band $C$, respectively), which was $<15 \%$ at 15,60 , and $120 \mathrm{~min}$ after conditioning (Fig. 5C; Cochran's $Q$ test: $15 \mathrm{~min}, Q=$
46.08, $\mathrm{df}=2, p<0.01 ; 60 \mathrm{~min}, Q=$ 41.33, $\mathrm{df}=2, p<0.01 ; 120 \mathrm{~min}, Q=$ $48.67, \mathrm{df}=2, p<0.01)$.

Context-dependent learning: rewarded odors reduce whereas rewarded contexts enhance neuronal firing

Next we wanted to understand how MB $\beta$ neurons responded to simple contextdependent learning. In the context learning, bees had to learn that only one context and one odor is rewarded. This experiment also had three phases (Fig. $6 A)$ like the previous experiment. In the preconditioning phase, the bee was puffed with three odors (A, B, and C) without US in each of two contexts (bright and dark). The protocol followed this sequence. Bright context was presented for $1 \mathrm{~min}$ followed by odors A, B, and C with 1 min between them. After $1 \mathrm{~min}$, bright context was turned off, which was the start of the second context, dark. In the dark context, odors $\mathrm{A}, \mathrm{B}$, and $\mathrm{C}$ were puffed again with an interstimulus interval of $1 \mathrm{~min}$. The trial ended when room lights were turned on, which was different from bright context. The preconditioning phase consisted of two such trials. In the conditioning phase, the bee was presented with two odors (A and B) in each context (bright and dark). The protocol started by presentation of bright context for $1 \mathrm{~min}$ followed by odor A, which was rewarded with US, and after $2.5 \mathrm{~min}$, B was puffed without US. After $1 \mathrm{~min}$, bright context was turned off, which started the second context, dark. In this context, both odors A and B were not rewarded. The interstimulus interval was 2.5. The trial ended when room lights were turned on. Conditioning phase consisted of five such trials. The postconditioning phase was the same as the preconditioning phase, except that bees were presented with extinction trials at 15,60 , and $120 \mathrm{~min}$ after the last conditioning trial. The order of context and odor presentations changed from experiment to experiment.

For the control animals, the procedure was exactly the same as above except that they were not rewarded during the entire experiment. PERs were noted during the preconditioning, conditioning, and postconditioning phase. The change in neuronal responses toward odors and contexts between preconditioning and postconditioning phases were compared by calculating the $\Delta$ SFR across phases.

The change in neuronal response toward the rewarded odor $(\mathrm{A}+)$ in the rewarded context became significantly negative compared with other odors at 60 and 120 min after conditioning (Fig. $6 B$; two-way repeated-measures ANOVA: 60 and $120 \mathrm{~min}, p<$ 0.01; overall effect, $\left.F_{(5,294)}=294.9\right)$. The change in neuronal response toward the rewarded context alone was significantly more positive compared with the unrewarded context as measured in the extinction trials 15,60 , and 120 min after conditioning (two-way repeated-measures ANOVA: 15, 60, and $120 \mathrm{~min}$, $p<0.01$; overall effect, $\left.F_{(1,98)}=1457\right)$. In addition, the change in neuronal response was negative toward rewarded odors at 60 and $120 \mathrm{~min}$ (one-sample $t$ test: $60 \mathrm{~min}, p<0.01, t=17.20$, $\mathrm{df}=49$; $120 \mathrm{~min}, p<0.01, t=52.44, \mathrm{df}=49)$ and positive toward rewarded contexts at 15, 60, and 120 min (one-sample $t$ test: 15 


\section{Context-dependent learning}
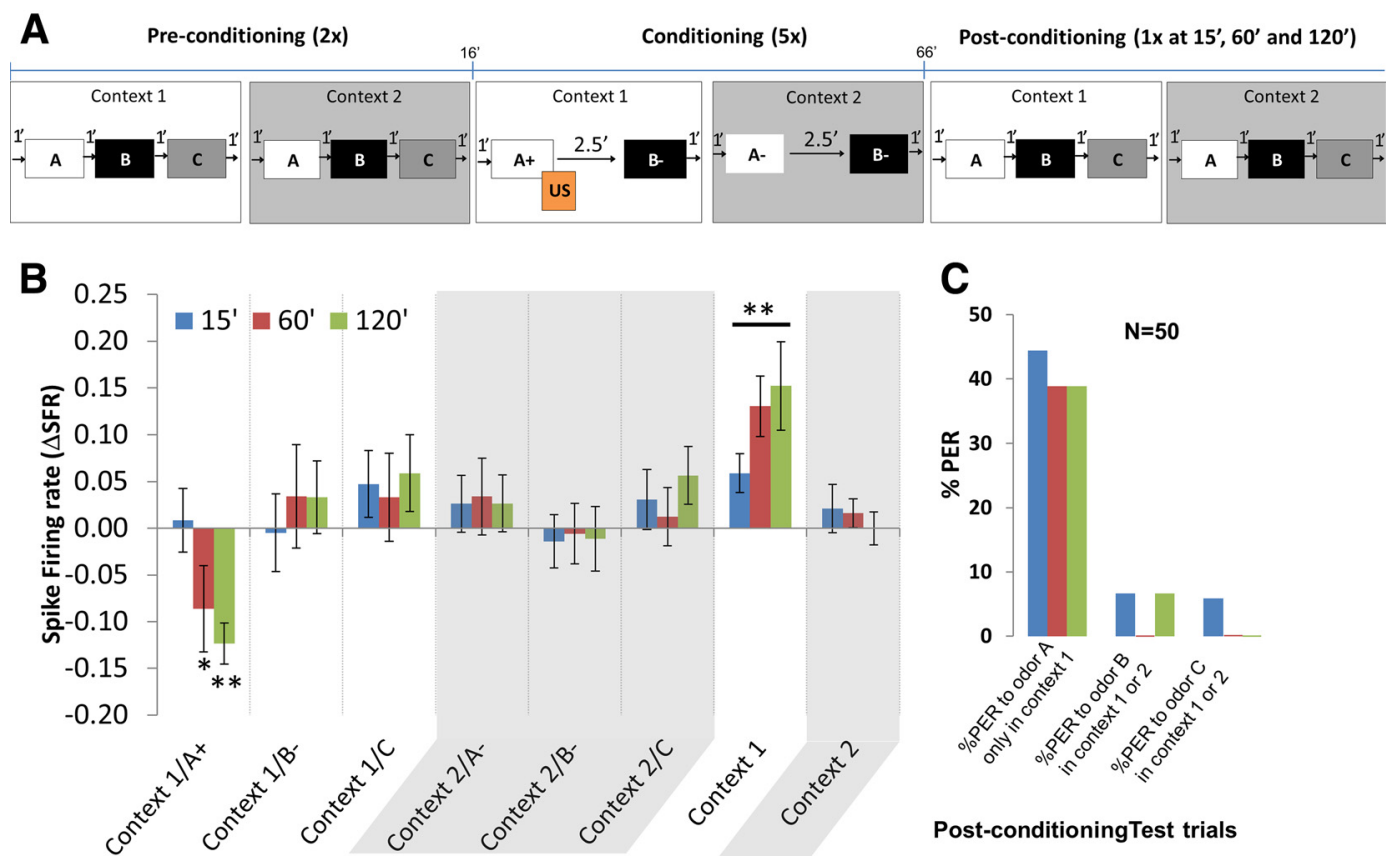

Post-conditioningTest trials

Figure 6. A, Context-dependent learning. Preconditioning phase: bees were presented with context 1 followed by odors $A, B$, and C. Context 1 was turned off and context 2 was presented followed by odors A, B, and C after which context 2 was turned off. This comprised one preconditioning trial, and the bees were subjected to two such trials. Conditioning phase: bees were presented with context 1 and odor $A$ was presented together with the sugar reward (US), whereas odor B was presented without any US. Context 1 was turned off and context 2 was presented after which the two odors A and B were presented without any US. Conditioning trial ended when context 2 was turned off. Bees were subjected to five conditioning trials. Postconditioning phase: same as preconditioning but each trial was presented once at 15,60 , and 120 min after conditioning. $B$, Change in neuronal response or $\Delta S F R$ toward odor $A$ in context 1 (rewarded) was significantly reduced at 60 and 120 min after conditioning compared with the other two odors B and C (two-way repeated-measures ANOVA: 60 and 120 min, $p<0.01 ;$ overall effect, $F_{(5,294)}=294.9$ ). There was no difference in firing rate between odors $A, B$, and $C$ in context 2. Change in neuronal response toward context 1 increased at 15, 60, and 120 min after conditioning (two-way repeated-measures ANOVA: 15,60 , and $120 \mathrm{~min}, p<0.01$; overall effect, $\left.F_{(1,98)}=1457\right)$, whereas change in neuronal response toward context 2 remained unchanged. Plots show average $\Delta S F R$ for each group, and error bars represent SEM. C, Plot showing percentage PER at 15, 60, and 120 min after conditioning. First group of bars show percentage PER toward rewarded odor $A$ only in context 1 but not context 2 (Table 1); $\sim 40 \%$ of the bees learned the simple context learning rule. Second and third groups show percentage PER toward unrewarded odor $B$ and neutral odor $C$, respectively, in either context 1 or context 2. Less than $10 \%$ of the bees showed a preference toward odors $B$ and C. Cochran's $Q$ test for PERs toward $A$ versus $B$ and $C: 15$ min, $Q=36.11, d f=2, p<0.01 ; 60$ min, $Q=36.11$, $\mathrm{df}=2, p<0.01 ; 120 \mathrm{~min}, Q=32.95, \mathrm{df}=2, p<0.01$.

$\min , p<0.01, t=23.81, \mathrm{df}=49 ; 60 \mathrm{~min}, p<0.01, t=39.19$, $\mathrm{df}=49 ; 120 \mathrm{~min}, p<0.01, t=26.12, \mathrm{df}=49)$ when compared with a hypothetical $\triangle$ SFR of 0 . The firing rate toward odors in the unrewarded contexts was not significantly different. With respect to behavior (Fig. $6 \mathrm{C}$ ), at postconditioning trials 15, 60, and $120 \mathrm{~min}, \sim 40 \%$ bees learned the contexts correctly, i.e., they showed PER only toward the rewarded odor A in the rewarded context (context 1 ) and not toward odor A in unrewarded context (context 2). Percentage PER toward odors B and $\mathrm{C}$ was $<10 \%$ (Cochran's $Q$ test for PERs toward A versus $\mathrm{B}$ and $\mathrm{C} ; 15 \mathrm{~min}, \mathrm{Q}=36.11, \mathrm{df}=2, p<0.01 ; 60 \mathrm{~min}, Q=$ $36.11, \mathrm{df}=2, p<0.01 ; 120 \mathrm{~min}, Q=32.95$, $\mathrm{df}=2, p<0.01)$. Also, the control bees that were placed in two contexts without any reward showed no particular preference to the any odors in either context (data not shown).

\section{Context-dependent reversal learning}

We then looked at the change in neuronal response of $\mathrm{MB} \beta$ neurons during reversal learning. Like the previous experiments, there were three phases (Fig. 7A). In the preconditioning phase, the bee was puffed with a random sequence of three odors A, B and $\mathrm{C}$ without US in each of the two compound contexts, yellow $+32^{\circ} \mathrm{C}$ and blue $+19^{\circ} \mathrm{C}$. Bees were presented with the yellow + $32^{\circ} \mathrm{C}$ context for $1 \mathrm{~min}$ followed by odors $\mathrm{A}, \mathrm{B}$, and $\mathrm{C}$ with $1 \mathrm{~min}$ between them. After $1 \mathrm{~min}$, the yellow $+32^{\circ} \mathrm{C}$ context was turned off and the second context blue $+19^{\circ} \mathrm{C}$ was turned on. After 1 min, odors A, B, and C were puffed with an interstimulus interval of $1 \mathrm{~min}$. The trial ended when blue $+19^{\circ} \mathrm{C}$ context was turned off. The preconditioning phase consisted of two such trials. In the conditioning phase, the bee was subjected to two odors in each of these two contexts. The protocol was as follows: yellow $+32^{\circ} \mathrm{C}$ context was presented for $1 \mathrm{~min}$ followed by A, which was rewarded with US, and after $2.5 \mathrm{~min}$, B was puffed without US. After $1 \mathrm{~min}$, yellow $+32^{\circ} \mathrm{C}$ was turned off and the second context, blue $+19^{\circ} \mathrm{C}$, was turned on. This time odor B was rewarded, and after $2.5 \mathrm{~min}$, A was not rewarded. The trial ended when blue $+19^{\circ} \mathrm{C}$ context was turned off. The conditioning phase consisted of five such trials. In the postconditioning phase, the context and odor sequence was exactly the same as the preconditioning but with one extinction trial each at 15, 60, and $120 \mathrm{~min}$ after the conditioning phase. Note that the order of context and odor presentations changed from experiment to experiment. In the control animals, the procedure was exactly the same as above except that they were not rewarded during the entire experiment. PERs were noted down during the preconditioning, conditioning, and postconditioning phase.

Note that the normalization procedure (see Materials and Methods) cancels out the changes caused by temperature to the spike firing. Only a subset of the original data from $19^{\circ} \mathrm{C}$ could be 


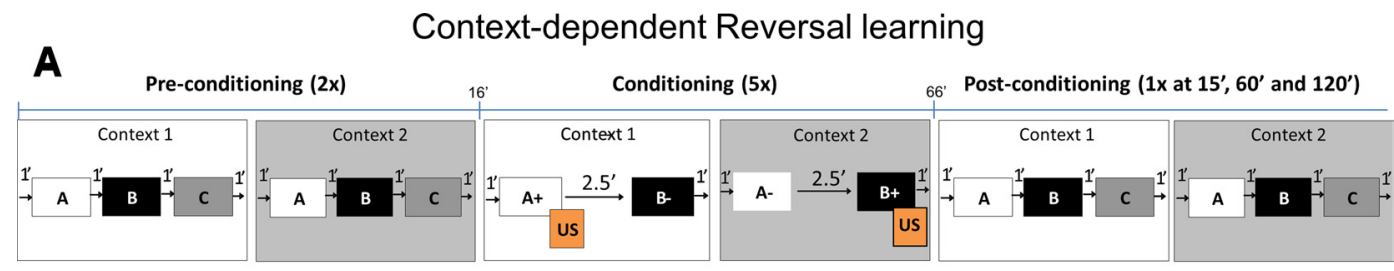

B

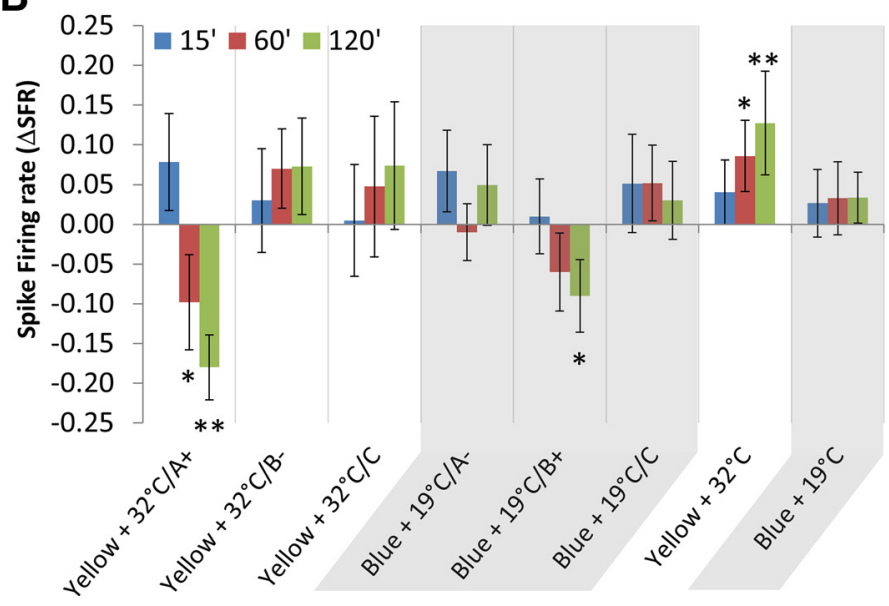

C

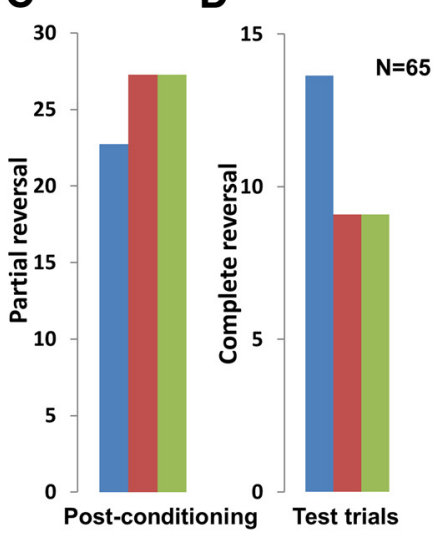

Figure 7. Context-dependent reversal learning. $A$, Preconditioning phase: bees were presented with context 1 for 1 min followed by odors A, B, and C. After 1 min, context 1 was turned off. Immediately context 2 was presented and odors A, B, and C were presented as in context 1 , and after 1 min context 2 was turned off. This comprised one preconditioning trial, and the bees were subjected to two such trials. Conditioning phase: bees were presented with context 1, and after $1 \mathrm{~min}$, odor A was presented together with the sugar reward (US) whereas odor B was presented without any US. After $1 \mathrm{~min}$, context 1 was turned off and immediately context 2 was turned on. In context 2, the rewards were reversed, i.e., the previously rewarded odor A was now not rewarded whereas odor $B$ was presented together with US. Context 2 was turned off after $1 \mathrm{~min}$. Bees were subjected to five conditioning trials. Postconditioning phase: same as preconditioning trials but each trial was presented once at 15,60 , and 120 min after conditioning. $\boldsymbol{B}$, The change in neuronal response measured as $\triangle$ SFR toward odor $A$ in context 1 (rewarded) were significantly reduced at 60 $\min (p<0.05)$ and $120 \min (p<0.01)$ after conditioning compared with odors B and C, whereas $\Delta$ SFR toward the rewarded odor B in context 2 was also reduced at 60 and 120 min (two-way repeated-measures ANOVA: odor A in yellow $+32^{\circ} \mathrm{C}$ context, $60 \mathrm{~min}, p<0.05$ and $120 \mathrm{~min}, p<0.01 ;$ odor $B$ in blue $+19^{\circ} \mathrm{C}$ context, $120 \mathrm{~min}, p<0.05 ;$ overall effect, $\left.F_{(5,384)}=11.01\right)$. The change in neuronal response toward context 1 increased at 60 and $120 \mathrm{~min}\left(p<0.01 ;\right.$ overall effect, $\left.F_{(1,128)}=7.985\right)$ but did not change in context 2. The abscissa gives the average $\Delta$ SFR for each group, and error bars represent SEM. C, Plot showing percentage partial reversal (Table 2 ) at 15, 60, and 120 min after conditioning; $>20 \%$ of the bees showed partial reversal. $D$, Plot showing percentage complete reversal at 15,60 , and 120 min after conditioning. More than $70 \%$ of the partial and complete reversals were in yellow $+32^{\circ} \mathrm{C}$ context. Cochran's $Q$ test for partial reversal: 15 min, $Q=$ $28.1333, \mathrm{df}=2, p<0.01 ; 60 \mathrm{~min}, Q=34.11, \mathrm{df}=2, p<0.01 ; 120 \mathrm{~min}, Q=34.11, \mathrm{df}=2, p<0.01 ;$ Cochran's $Q$ test for complete reversal: $15 \mathrm{~min}, Q=16.22, \mathrm{df}=2, p<0.01 ; 60 \mathrm{~min}, Q=$ $10.33, \mathrm{df}=2, p<0.01 ; 120 \mathrm{~min}, Q=10.33, \mathrm{df}=2, p<0.01$.

used $(\Delta \mathrm{SFR}>10 \mathrm{~Hz})$ because spiking was completely absent in some bees during the $19^{\circ} \mathrm{C}$ context.

During the yellow $+32^{\circ} \mathrm{C}$ context, the spike firing of $\mathrm{MB} \beta$ neurons toward the rewarded odor A was significantly reduced at 60 and $120 \mathrm{~min}$ after conditioning, whereas in blue $+19^{\circ} \mathrm{C}$ context firing rate toward the rewarded odor $\mathrm{B}$ was reduced only at 120 min (Fig. 7B; two-way repeated-measures ANOVA: odor A in yellow $+32^{\circ} \mathrm{C}$ context, $60 \mathrm{~min}, p<0.05 ; 120 \mathrm{~min}, p<0.01$; odor B in blue $+19^{\circ} \mathrm{C}$ context, $120 \mathrm{~min}, p<0.05$; overall effect, $\left.F_{(5,384)}=11.01\right)$. Although, both contexts were rewarded equally, spike firing toward the rewarded context yellow $+32^{\circ} \mathrm{C}$ was significantly increased at 60 and $120 \mathrm{~min}(p<0.01$; overall effect, $\left.F_{(1,128)}=7.985\right)$ after conditioning, whereas firing rate toward blue $+19^{\circ} \mathrm{C}$ context was not significant. This is probably because the bees did not learn the blue $+19^{\circ} \mathrm{C}$ context very well. In addition, the change in neuronal response was negative toward rewarded odors (one-sample $t$ test: yellow $+32^{\circ} \mathrm{C}, 60 \mathrm{~min}, p<$ $0.01, t=3.452, \mathrm{df}=64 ; 120 \mathrm{~min}, p<0.01, t=8.439$, $\mathrm{df}=64$; blue $+19^{\circ} \mathrm{C}, 120 \mathrm{~min}, p<0.01, t=2.403, \mathrm{df}=64$ ) and positive toward rewarded context yellow $+32^{\circ} \mathrm{C}$ (one-sample $t$ test: 15 $\min , p<0.01, t=2.188, \mathrm{df}=64 ; 60 \mathrm{~min}: p<0.01, t=3.582$, $\mathrm{df}=64 ; 120 \mathrm{~min}, p<0.01, t=4.145, \mathrm{df}=64)$ when compared with a hypothetical $\Delta$ SFR of 0 . With respect to learning the reversal rule (Table 2), $\sim 37 \%$ of the bees showed partial reversal during the conditioning trials (data not shown) and 25\% (Fig. $7 C$ ) of the bees showed partial reversal during the three extinction trials in the postconditioning phase (Cochran's $Q$ test: $15 \mathrm{~min}, Q=$ 28.1333, $\mathrm{df}=2, p<0.01 ; 60 \mathrm{~min}, Q=34.11, \mathrm{df}=2, p<0.01 ; 120$ min, $Q=34.11, \mathrm{df}=2, p<0.01)$. Also, $\sim 10 \%$ showed complete reversal (Cochran's $Q$ test: $15 \mathrm{~min}, Q=16.22, \mathrm{df}=2, p<0.01 ; 60$ $\min , Q=10.33, \mathrm{df}=2, p<0.01 ; 120 \mathrm{~min}, Q=10.33, \mathrm{df}=2, p<$ 0.01 ). More than $70 \%$ of the bees learned the reversal learning rule better in the yellow $+32^{\circ} \mathrm{C}$ context than in the blue $+19^{\circ} \mathrm{C}$ context. The control bees that were placed in the context but not rewarded showed no preference to any particular context.

Finally, to understand the relationship between learning and neuronal activity, we correlated the learning scores with neuronal activity using Pearson's product moment correlation coefficient function. We first sorted the learning scores into groups such as $0-10 \%, 10-20 \%$, and so forth and then averaged the entire neuronal data for each group of learning score. In the case of odors, we used PERs (from olfactory differential learning and contextdependent learning experiments), partial and complete reversals (from reversal learning experiment) as learning scores. We found a strong negative correlation (Pearson's correlation coefficient: $R^{2}=0.89$ ) between learning scores and $\Delta$ SFR toward rewarded odors (Fig. $8 \mathrm{~A}$ ). Although we did not note the PERs during the contexts itself, we could use the PER data from odors in a particular context for the correlation analysis. Hence, we used PERs (from context-dependent learning experiments), partial and 
Neuronal firing as a function of learning

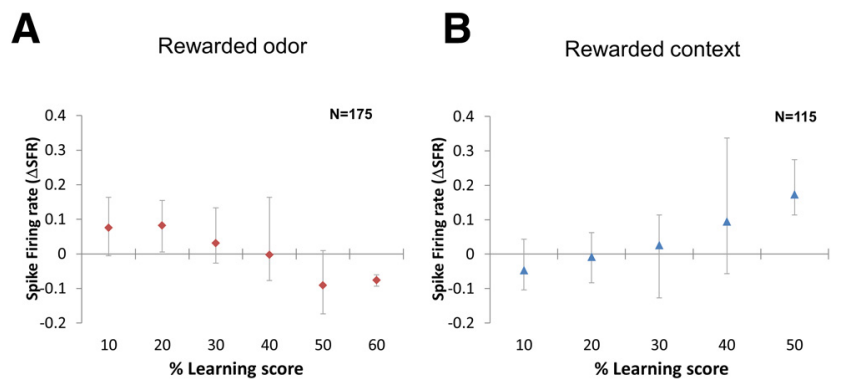

Figure 8. Change in neuronal responses toward rewarded odors and contexts as a function of learning. $A$, We grouped data based on learning scores (percentage PER in differential odor and context-dependent learning or percentage partial and percentage complete reversals in reversal learning) toward rewarded odors. We looked at corresponding change in neuronal responses after odor onset and found that learning and $\triangle$ SFR were negatively correlated (Pearson's correlation coefficient, $R^{2}=0.89$ ), i.e., with increase in learning the firing rate decreased. $B$, Similarly for the contexts, based on learning scores toward the odors (percentage PER in context-dependent learning or percentage partial and percentage complete reversals in reversal learning), we grouped the data and looked at corresponding firing rates after context onset. We found a positive correlation $\left(R^{2}=0.96\right)$ between learning and firing rate, i.e., with increase in learning firing rate also increased. The ordinate gives the average $\triangle$ SFR for each group of learning score. The bottom and top error bars represent minimum and maximum values, respectively.

complete reversals (from reversal learning experiment) as learning scores. We observed a strong positive correlation $\left(R^{2}=0.96\right)$ between learning scores and $\triangle$ SFR toward rewarded contexts (Fig. 8B).

\section{Discussion}

Context learning is a term widely used for describing conditional discriminations that can be subsumed in the so-called occasion setting problem (Schmajuk et al., 1998). In this problem, a given stimulus, the occasion setter, informs the animal about the outcome of its choice. For instance, another form of occasion setting involving two occasion setters is the so-called transwitching problem. In this problem, an animal is trained differentially with two stimuli, $\mathrm{A}$ and $\mathrm{B}$, and with two different occasion setters $\mathrm{C} 1$ and $\mathrm{C} 2$. When $\mathrm{C} 1$ is available, stimulus $\mathrm{A}$ is rewarded whereas stimulus $B$ is not ( $A+$ vs $B-)$, whereas it is the opposite ( $A-$ vs $\mathrm{B}+$ ) with $\mathrm{C} 2$. Focusing on the elements alone does not allow solving the problem because each element (A, B) appears equally as often rewarded and nonrewarded. Each occasion setter (C1, $\mathrm{C} 2)$ is, in the same way, simultaneously rewarded and nonrewarded, depending on its association with A or B. Therefore, animals have to learn that $\mathrm{C} 1$ and $\mathrm{C} 2$ define the valid contingency and transwitching problem is considered a form of context learning because these occasion setters can be viewed as contexts determining the appropriateness of each choice.

Free-flying honeybees were found to solve various forms of context learning, including transwitching problems (for review, see Giurfa, 2003; Menzel, 2007). Restrained bees learn combinations of olfactory stimuli well and were found to follow a modified unique cue rule in binary odor mixture learning (Deisig et al., 2003). It has been shown that colors as context stimuli modulate odor learning in such a way that correct visual/odor combinations are learned and remembered better (Gerber and Smith, 1998). We introduced another context, temperature, that bees are known to associate as a cue together with a reward (Menzel et al., 2001).

We found that restrained honeybees learn context-dependent tasks and that the firing rate of the same MB extrinsic neurons is enhanced for rewarded contexts and reduced for rewarded cues. We addressed the unresolved problem of how elements of cue/ context compounds are integrated neurally, as separate elements developing their specific associative strengths as proposed by Rescorla (1972), or as unique configurations that develop their respective combined associative strength as proposed by Pearce (1994)? Our data appear to support the Rescorla-Wagner model on a neural level opposing the interpretation of behavioral data in bees about learning of odor configurations (Lachnit, 2004).

We first found that context-dependent reversal learning lead to better and faster learning if two contexts were combined. The bees responded more quickly (third trial) toward the combined contexts and slowly (fourth or fifth trial) toward single contexts, indicating that combined contexts are easier to learn than a single context. Learning of the reversal of this transwitching rule was difficult; bees had to learn first to respond to an odor in one context and had to ignore the same odor in another context and later reverse this rule. Motivation dropped rather quickly because the bees were rewarded in both contexts equally and within a very short time (two times in $10 \mathrm{~min}$ ). Toward the end of conditioning, we observed an overlearning reduction effect (Reid, 1953; Capaldi and Stevenson, 1957) in the high temperature context group in which the learning scores saturated early in the conditioning phase and improve only slightly. Additional studies are needed to examine drop in performance after overlearning as suggested by Yerkes and Dodson (1908).

In our search for neural correlates of context-dependent forms of learning, we focused on $\mathrm{MB}$ extrinsic neurons exiting the $\alpha \mathrm{L}$ in its ventral aspect ( $\beta$ exit). The MB is known to be involved in learning, memory formation, and memory retrieval in the honeybee (Menzel et al., 2006) and Drosophila (Davis, 2011), and it can be expected that extrinsic neurons provide a readout of the learned induced neural restructuring within the MB. The MB $\beta$ neurons have been recorded several times in the past and were found to change their response properties during olfactory conditioning (Mauelshagen, 1993; Grunewald, 1999; Okada et al., 2007; Haehnel and Menzel, 2010, 2012; Strube-Bloss et al., 2011). Simple differential conditioning experiments uncovered several associative phenomena. After conditioning, the ISIs during spontaneous activity reduced or, in other words, $\triangle$ SFR increased, and the firing became more stable (smaller deviations) (Fig. $4 E$ ). When we switched to context-dependent learning using temperature as a context stimulus, we needed to determine temperature dependence of neuronal activity. We found that heating $\left(32^{\circ} \mathrm{C}\right)$ increased the spike firing and cooling $\left(19^{\circ} \mathrm{C}\right)$ decreased or abolished spike firing (Fig. $\left.4 C, D\right)$. Honeybees sense temperature by thermoreceptive sensillae on the antennae (Yokohari, 1983); possibly sensory input from thermosensillae provides a neural drive that is required for central processing, which leads to change in firing rates at different temperatures. Even neurons in the mammalian brain are highly sensitive to body temperature, for example, the neuronal activity in the hippocampus increases with temperature (Moser et al., 1993).

Our olfactory differential conditioning corroborated previous findings that neuronal response decreases toward the learned odor (Okada et al., 2007). In this respect, the recorded neurons resemble properties of the PE1 but not of other neurons recorded in the same area (Strube-Bloss et al., 2011). In the first contextdependent conditioning combined with $\mathrm{MB} \beta$ neuron recordings, we used bright and dark contexts in which only one of the two odors in one of two contexts was rewarded. Similar to the behavior experiments, bees learned this simple rule quickly. The 
change in neuronal response of $\mathrm{MB} \beta$ neurons specifically was negative toward rewarded odors and positive toward rewarded contexts. Then we tested context-dependent reversal learning in which bees had to learn to reverse their responses in each context. During conditioning, we rewarded two different odors in two different contexts. For example, odor A was rewarded in yellow + $32^{\circ} \mathrm{C}$ context and odor $\mathrm{B}$ was rewarded in blue $+19^{\circ} \mathrm{C}$ context. Bees showed a bias toward yellow $+32^{\circ} \mathrm{C}$ context and hence quickly learned odor $\mathrm{A}$ in yellow $+32^{\circ} \mathrm{C}$ context much better than odor $\mathrm{B}$ in blue $+19^{\circ} \mathrm{C}$ context. The change in neuronal response toward rewarded odor in yellow $+32^{\circ} \mathrm{C}$ context was negative at 60 and $120 \mathrm{~min}$ after conditioning, whereas the responses toward the rewarded odor in blue $+19^{\circ} \mathrm{C}$ context was negative only at $120 \mathrm{~min}$. The neuronal response toward contexts was opposite, the change in neuronal responses toward the yellow $+32^{\circ} \mathrm{C}$ context was significantly positive, whereas no change was seen toward blue $+19^{\circ} \mathrm{C}$ context, corroborating at least in part what was found with simpler form of context-dependent learning, namely that firing rates of $\mathrm{MB} \beta$ neurons are different for the cue and the context. Thus, we showed for the first time that the properties of $\mathrm{MB} \beta$ neurons are qualitatively different toward the rewarded cue context.

We also asked whether neuronal plasticity to the cue and the context depends on the amount of learning the task and found that the change in neuronal response to the learned cues correlated negatively with increasing learning scores for the cues and positively with increasing learning scores for contexts (Fig. 8).

Rewarded cues and context are obviously processed differently. In mammals, it has been shown that cued learning and context-dependent learning are related to different neural mechanisms (Phillips and LeDoux, 1992). It appears that contextdependent learning requires an intact hippocampus (Chen et al., 1996; Logue et al., 1997; Holland and Bouton, 1999; Anagnostaras et al., 2001; Corcoran and Maren, 2001), whereas cued learning does not require the hippocampus (Gould et al., 2002). In insects, visual and olfactory learning may involve the $\mathrm{MB}$ differently. Simple forms of visual learning are independent of the $\mathrm{MB}$, but simple forms of olfactory learning require the $\mathrm{MB}$ (Heisenberg, 2003) whereas more complex forms of visual learning depend on a functional MB (Ren et al., 2012). In honeybees, the function of the $\mathrm{MB}$ can be compromised without significant loss of simple olfactory learning tasks (Scheiner et al., 2001; Malun et al., 2002), but complex forms of olfactory learning (e.g., side specific learning) depend on MB (Komischke et al., 2005). These results indicate the involvement of the MBs in solving elemental olfactory tasks whose complexity is enhanced by virtue of the number of stimuli, possibly by an effect on the inhibition of information exchange between brain hemispheres (Menzel, 2007). Nothing is known so far with respect to the $\mathrm{MB}$ function in visual and context learning, but it can be tentatively concluded that the full MB function is required for configural forms of learning, most likely including context-specific learning.

The picture emerging from our data is that the MB is a highly adaptive, high-order coding device that integrates across multiple sensory modalities, organizes associative plasticity of its intrinsic neurons according to the value of stimulus combinations and categorizes stimuli with respect to their indicative functions as cue and context. The differential coding of cues and contexts supports the view that the elements of stimulus combinations are processed separately, keeping a neural trace of their meaning in the stream of naturally occurring stimuli.

\section{References}

Anagnostaras SG, Gale GD, Fanselow MS (2001) Hippocampus and contextual fear conditioning: recent controversies and advances. Hippocampus 11:8-17. CrossRef Medline

Bitterman ME, Menzel R, Fietz A, Schäfer S (1983) Classical conditioning of proboscis extension in honeybees (Apis mellifera). J Comp Psychol 97: 107-119. CrossRef Medline

Capaldi EJ, Stevenson HW (1957) Response reversal following different amounts of training. J Comp Physiol Psychol 50:195-198. CrossRef Medline

Chen C, Kim JJ, Thompson RF, Tonegawa S (1996) Hippocampal lesions impair contextual fear conditioning in two strains of mice. Behav Neurosci 110:1177-1180. CrossRef Medline

Cohen JD, Barch DM, Carter C, Servan-Schreiber D (1999) Contextprocessing deficits in schizophrenia: converging evidence from three theoretically motivated cognitive tasks. J Abnorm Psychol 108:120-133. CrossRef Medline

Corcoran KA, Maren S (2001) Hippocampal inactivation disrupts contextual retrieval of fear memory after extinction. J Neurosci 21:1720-1726. Medline

Davis RL (2011) Traces of Drosophila memory. Neuron 70:8-19. CrossRef Medline

Deisig N, Lachnit H, Sandoz JC, Lober K, Giurfa M (2003) A modified version of the unique cue theory accounts for olfactory compound processing in honeybees. Learn Mem 10:199-208. CrossRef Medline

Galizia CG, Joerges J, Küttner A, Faber T, Menzel R (1997) A semi-in-vivo preparation for optical recording of the insect brain. J Neurosci Methods 76:61-69. CrossRef Medline

Gaskin S, Chai SC, White NM (2005) Inactivation of the dorsal hippocampus does not affect learning during exploration of a novel environment. Hippocampus 15:1085-1093. CrossRef Medline

Gerber B, Menzel R (2000) Contextual modulation of memory consolidation. Learn Mem 7:151-158. Medline

Gerber B, Smith BH (1998) Visual modulation of olfactory learning in honeybees. J Exp Biol 201:2213-2217. Medline

Giurfa M (2003) Cognitive neuroethology: dissecting non-elemental learning in a honeybee brain. Curr Opin Neurobiol 13:726-735. CrossRef Medline

González F, Quinn JJ, Fanselow MS (2003) Differential effects of adding and removing components of a context on the generalization of conditional freezing. J Exp Psychol Anim Behav Process 29:78-83. CrossRef Medline

Gould TJ, Rowe WB, Heman KL, Mesches MH, Young DA, Rose GM, Bickford PC (2002) Effects of hippocampal lesions on patterned motor learning in the rat. Brain Res Bull 58:581-586. CrossRef Medline

Gronenberg W (1986) Physiological and anatomical properties of optical input-fibres to the mushroom body in the bee brain. J Insect Physiol 32:695-704. CrossRef

Grunewald B (1999) Physiological properties and response modulations of mushroom body feedback neurons during olfactory learning in the honeybee, Apis mellifera. J Comp Physiol A Neuroethol Sens Neural Behav Physiol 185:565-576. CrossRef

Haehnel M, Menzel R (2010) Sensory representation and learning-related plasticity in mushroom body extrinsic feedback neurons of the protocerebral tract. Front Syst Neurosci 4:161. CrossRef Medline

Haehnel M, Menzel R (2012) Long-term memory and response generalization in mushroom body extrinsic neurons in the honeybee Apis mellifera. J Exp Biol 215:559-565. CrossRef Medline

Heisenberg M (2003) Mushroom body memoir: from maps to models. Nat Rev Neurosci 4:266-275. CrossRef Medline

Hirsh R (1974) The hippocampus and contextual retrieval of information from memory: a theory. Behav Biol 12:421-444. CrossRef Medline

Holland PC, Bouton ME (1999) Hippocampus and context in classical conditioning. Curr Opin Neurobiol 9:195-202. CrossRef Medline

Kesner RP, Hardy JD, Novak JM (1983) Phencyclidine and behavior: II. Active avoidance learning and radial arm maze performance. Pharmacol Biochem Behav 18:351-356. CrossRef Medline

Komischke B, Giurfa M, Lachnit H, Malun D (2002) Successive olfactory reversal learning in honeybees. Learn Mem 9:122-129. CrossRef Medline

Komischke B, Sandoz JC, Malun D, Giurfa M (2005) Partial unilateral lesions of the mushroom bodies affect olfactory learning in honeybees Apis mellifera L. Eur J Neurosci 21:477-485. CrossRef Medline

Lachnit H (2004) Odor processing in honeybees: is the whole equal to, more 
than, or different from the sum of its parts? (Slater PJ, Rosenblatt JS, Roper TJ, Snowdon CT, Brockmann HJ, Naguib M, eds), pp 241-264. Amsterdam: Elsevier.

Logue SF, Paylor R, Wehner JM (1997) Hippocampal lesions cause learning deficits in inbred mice in the Morris water maze and conditioned-fear task. Behav Neurosci 111:104-113. CrossRef Medline

Malun D, Giurfa M, Galizia CG, Plath N, Brandt R, Gerber B, Eisermann B (2002) Hydroxyurea-induced partial mushroom body ablation does not affect acquisition and retention of olfactory differential conditioning in honeybees. J Neurobiol 53:343-360. CrossRef Medline

Matsumoto Y, Mizunami M (2004) Context-dependent olfactory learning in an insect. Learn Mem 11:288-293. CrossRef Medline

Mauelshagen J (1993) Neural correlates of olfactory learning paradigms in an identified neuron in the honeybee brain. J Neurophysiol 69:609-625. Medline

Menzel R (2007) Cognition in invertebrates. In: Evolution of nervous systems, Vol II, Evolution of nervous systems in invertebrates (Kaas JH, eds), pp 403-422. Oxford, UK: Academic.

Menzel R (2012) The honeybee as a model for understanding the basis of cognition. Nat Rev Neurosci 13:758-768. CrossRef Medline

Menzel R, Giurfa M (2001) Cognitive architecture of a mini-brain: the honeybee. Trends Cogn Sci 5:62-71. CrossRef Medline

Menzel R, Manz G, Menzel R, Greggers U (2001) Massed and spaced learning in honeybees: the role of CS, US, the intertrial interval, and the test interval. Learn Mem 8:198-208. CrossRef Medline

Menzel R, Leboulle G, Eisenhardt D (2006) Small brains, bright minds. Cell 124:237-239. CrossRef Medline

Mizunami M, Okada R, Li Y, Strausfeld NJ (1998) Mushroom bodies of the cockroach: activity and identities of neurons recorded in freely moving animals. J Comp Neurol 402:501-519. CrossRef Medline

Moser E, Mathiesen I, Andersen P (1993) Association between brain temperature and dentate field potentials in exploring and swimming rats. Science 259:1324-1326. CrossRef Medline

Odling-Smee FJ (1975) Background stimuli and the inter-stimulus interval during pavlovian conditioning. Q J Exp Psychol 27:387-392. CrossRef Medline

Okada R, Ikeda J, Mizunami M (1999) Sensory responses and movementrelated activities in extrinsic neurons of the cockroach mushroom bodies. J Comp Physiol A Neuroethol Sens Neural Behav Physiol 185:115-129. CrossRef

Okada R, Rybak J, Manz G, Menzel R (2007) Learning-related plasticity in PE1 and other mushroom body-extrinsic neurons in the honeybee brain. J Neurosci 27:11736-11747. CrossRef Medline

Pearce JM (1994) Discrimination and categorization. In: Animal learning and cognition. Handbook of perception and cognition, Ed 2 (Mackintosh NJ, ed). San Diego: Academic.

Phillips RG, LeDoux JE (1992) Differential contribution of amygdala and hippocampus to cued and contextual fear conditioning. Behav Neurosci 106:274-285. CrossRef Medline

Reid LS (1953) The development of noncontinuity behavior through continuity learning. J Exp Psychol 46:107-112. CrossRef Medline

Ren Q, Li H, Wu Y, Ren J, Guo A (2012) A GABAergic inhibitory neural circuit regulates visual reversal learning in Drosophila. J Neurosci 32: 11524-11538. CrossRef Medline

Rescorla RA (1972) A theory of classical conditioning: variations in the effectiveness of reinforcement and non-reinforcement. In: Classical conditioning II: current research and theory (Black AH, Prokasy WF, eds). New York: Appleton-Century-Crofts.

Riccio DC, Ackil J, Burch-Vernon A (1992) Forgetting of stimulus attributes: methodological implications for assessing associative phenomena. Psychol Bull 112:433-445. CrossRef Medline

Rybak J, Menzel R (1993) Anatomy of the mushroom bodies in the honey bee brain: the neuronal connections of the alpha-lobe. J Comp Neurol 334:444-465. CrossRef Medline

Sato C, Matsumoto Y, Sakura M, Mizunami M (2006) Contextual olfactory learning in cockroaches. Neuroreport 17:553-557. CrossRef Medline

Scheiner R, Weiß A, Malun D, Erber J (2001) Learning in honey bees with brain lesions: how partial mushroom-body ablations affect sucrose responsiveness and tactile antennal learning. Anim Cogn 3:227-235. CrossRef

Schmajuk NA, Lamoureux JA, Holland PC (1998) Occasion setting: a neural network approach. Psychol Rev 105:3-32. CrossRef Medline

Strube-Bloss MF, Nawrot MP, Menzel R (2011) Mushroom body output neurons encode odor-reward associations. J Neurosci 31:3129-3140. CrossRef Medline

Tulving E, Thomson DM (1973) Encoding specificity and retrieval processes in episodic memory. Psychol Rev 80:352-373. CrossRef

Umbricht D, Schmid L, Koller R, Vollenweider FX, Hell D, Javitt DC (2000) Ketamine-induced deficits in auditory and visual context-dependent processing in healthy volunteers: implications for models of cognitive deficits in schizophrenia. Arch Gen Psychiatry 57:1139-1147. CrossRef Medline

von Frisch K (1967) The dance language and orientation of bees. Cambridge, MA: Harvard UP.

Yerkes RM, Dodson JD (1908) The relation of strength of stimulus to rapidity of habit-formation. J Comp Neurol Psychol 18:459-482. CrossRef

Yokohari F (1983) The coelocapitular sensillum, an antennal hygro- and thermoreceptive sensillum of the honey bee, Apis mellifera L. Cell Tissue Res 233:355-365. Medline 